\title{
CARACTERIZAÇÃO DAS SENTENÇAS CONDENATÓRIAS DO CRIME DE TRÁFICO DE DROGAS EM BELÉM, PARÁ, BRASIL
}

\section{RENATA VALERIA PINTO CARDOSO LISBOA}

Mestra em Segurança Pública pela Universidade Federal do Pará; Especialista em Direito Agrário pelo CESUPA-Pará; Especialista em Direito Administrativo pela Escola Superior de Advocacia-ESA-Pará; Possui graduação em Direito pela Universidade da Amazônia (2003). Atualmente é Promotora de Justiça do Ministério Público do Estado do Pará. Tem experiência na área de Direito, com ênfase nas áreas de Direito Penal, Processual Penal e Infância e Juventude.

\section{EDSON MARCOS LEAL SOARES RAMOS}

É Doutor em Engenharia de Produção pela Universidade Federal de Santa Catarina e Professor do Programa de PósGraduação em Segurança Pública do Instituto de Filosofia e Ciências Humanas da Universidade Federal do Pará, Belém, Pará, Brasil.

\section{MARCUS ALAN DE MELO GOMES}

É Pós-Doutor pelo Centro de Direitos Humanos da Universidade de Coimbra- Portugal e Professor do Programa de PósGraduação em Segurança Pública do Instituto de Filosofia e Ciências Humanas da Universidade Federal do Pará, Belém, Pará, Brasil.

\section{MAÉLY FERREIRA DE HOLANDA RAMOS}

É Doutora em Teoria e Pesquisa do Comportamento - Psicologia (UFPA) e Professora do Programa de Pós-Graduação em Segurança Pública do Instituto de Filosofia e Ciências Humanas da Universidade Federal do Pará, Belém, Pará, Brasil.

\section{RESUMO}

O artigo apresenta a configuração de sentenças condenatórias tendo em vista a relevância em fomentar pesquisas que possuam como objeto o crime de tráfico de drogas. O objetivo deste estudo é caracterizar as sentenças condenatórias do crime de tráfico de drogas, da Vara de Combate ao Crime Organizado de Belém (PA) em 2017. Para tanto, realizou-se análise de conteúdo das sentenças de tráfico de drogas, com base na criminologia crítica, a fim de entender como ocorre a seleção das pessoas criminalizadas. Os resultados evidenciaram particularidades que indicam elementos caracterizadores do crime de tráfico de drogas e apontam como circunstâncias predominantes a utilização do depoimento de policiais para fundamentar a condenação.

Palavras-Chave: Depoimento de policiais; Denúncia anônima; Atitude suspeita; Cocaína.

\section{ABSTRACT \\ CHARACTERIZATION OF THE CONDEMNATING JUDGMENTS OF THE CRIME OF DRUG TRAFFICKING IN BELÉM, PARÁ, BRAZIL}

This study seeks to present the configuration of convictions in view of the relevance of promoting research that has as its object the crime of drug trafficking. The purpose of this study is to characterize the convictions of the crime of drug trafficking, of the fight against organized crime in Belém-Pará, in 2017. For this purpose, a Content 
Analysis of data extracted from convictions of crime of drug trafficking. The results showed particularities that indicate elements that characterize the crime of drug trafficking and point out as the predominant circumstances the use of police testimony to substantiate the conviction.

Keywords: Police testimony; Anonymous report; Suspicious attitude; Cocaine.

DOI: 10.31060/rbsp.2020.v14.n2.1129

Data de recebimento: 01/04/2019 - Data de aprovação: 25/03/2020

\section{INTRODUÇÃO}

O século XX figura como um marco da política proibicionista de drogas, principalmente a partir da década de 70, quando o presidente dos Estados Unidos Richard Nixon implementou uma política de guerra às drogas (KARAM, 2017, p. 212). Após mais de 100 anos do implemento do paradigma proibicionista, não conseguiu impedir que as pessoas usem substâncias entorpecentes, tampouco reduziu a oferta de tais substâncias (BOITEUX; PADUA, 2012). Estima-se que mais de 275 milhões de pessoas no mundo tenham usado drogas pelo menos uma vez em 2016, um aumento de 20 milhões de pessoas em comparação a 2015. Além disso, a droga mais utilizada no mundo foi a maconha, a qual teve seu cultivo e produção ampliados no período de 2010 a 2016 (UNODC, 2018).

A Lei n 11.343/2006 (BRASIL, 2006), atualmente em vigor, aumentou a repressão penal em relação ao crime de tráfico de drogas, apesar de ter avançado em relação à legislação anterior, ao despenalizar a posse de drogas para uso próprio. A despeito do recrudescimento da legislação antidrogas, verifica-se que as ocorrências criminais crescem proporcionalmente às taxas de encarceramento, desta feita, conclui-se que prender não reduz a taxa de criminalidade (MONTEIRO; CARDOSO, 2013). O Brasil já ultrapassou a marca de 700 mil presos, em junho de 2016, o que representa um aumento de 707\% em relação ao total registrado no início dos anos 1990 (BRASIL, 2017c).

O aumento da intervenção penal passou a ser apontada como a solução para os anseios por segurança individual, sendo a proibição das drogas tornadas ilícitas o principal propiciador da expansão do poder punitivo na contemporaneidade (KARAM, 2017). O traficante de drogas passou a ser apontado como inimigo a ser combatido, discurso disseminado pela mídia e pelas agências de controle social formal e informal, que corroboram a lógica de estigmatizar o traficante de drogas pertencente às classes mais desfavorecidas e reproduzem a exclusão social dos grupos mais vulneráveis (SANTOS; BROCCO, 2016).

A taxa de aprisionamento aumentou 157\% no Brasil, entre 2000 e 2016 (BRASIL, 2017c). O crime de tráfico de drogas é o segundo que mais leva à prisão e corresponde a $26 \%$ e $62 \%$ dos crimes pelos quais os homens e mulheres, respectivamente, foram condenados ou aguardam julgamento, ficando atrás apenas dos crimes de roubo e furto, que correspondem a 37\% das incidências entre os homens e $20 \%$ entre as mulheres (BRASIL, 2017c). O aumento da população carcerária registrado nos últimos anos tem levado a graves consequências, tanto econômicas, em relação ao aumento de gastos penitenciários, como humanos, uma vez que os presos são submetidos a condições subumanas (BOITEUX, 2014).

Nessa perspectiva, este artigo visa caracterizar as sentenças condenatórias do crime de tráfico de drogas, da Vara de Combate ao Crime Organizado de Belém (PA), em 2017. A hipótese é de que as agências policiais têm papel fundamental na criminalização por tráfico de drogas na cidade de Belém, uma vez que é a partir dos elementos trazidos pelos policiais aos autos que se desenvolve toda a instrução criminal. 
Apesar da existência de estudos doutrinários nesse sentido, há uma carência de estudos empíricos a respeito do assunto, razão pela qual surgiu o interesse para a realização deste trabalho. Assim, o artigo está organizado em cinco partes. Após a introdução, discorre-se sobre a teoria do labelling approach e direito penal do inimigo, no âmbito do tratamento do proibicionismo de drogas. Em seguida, descreve-se a metodologia da pesquisa, analisam-se os resultados e colocam-se discussões e conclusões a partir das descobertas da pesquisa.

\section{A TEORIA DO LABELLING APPROACHE O DIREITO PENAL DO INIMIGO APLICADOS AO TRÁFICO DE DROGAS}

A teoria do etiquetamento ou labelling approach, desenvolvida por Becker (2008), analisa o processo de atribuição da etiqueta ou do rótulo de criminoso a certas pessoas e o impacto que tal atribuição teria na pessoa, a partir disso. O enfoque do criminoso é deslocado para o controle social e sustenta-se que a criminalidade não é a qualidade de uma determinada conduta, mas o resultado de um determinado processo de estigmatização da conduta e da pessoa que a praticou (CONDE; HASSEMER, 1985). Logo, o estudo desta teoria é importante para a compreensão da atuação das instâncias oficiais na sua função constitutiva da criminalidade (BARATTA, 2016).

Desta maneira, a criminalidade se mostra como uma condição atribuída a determinado sujeito, com base na definição jurídica do crime e a seleção que estigmatiza o agente como criminoso, entre todos aqueles que praticam a mesma conduta (ANDRADE, 2015). Nesse sentido, Becker (2008) mostra que os outsiders são as pessoas entendidas como desviantes por outras e que não se encaixam no círculo de membros normais do grupo. Do ponto de vista das pessoas estigmatizadas como desviantes, os outsiders podem ser aqueles que fazem as regras que eles mesmos seriam culpados por violar. O desvio, portanto, aparece como uma relação social, não como uma qualidade que reside no comportamento, mas como uma interação da pessoa que comete um ato e aqueles que reagem ao mesmo ato.

Atualmente, a sensação geral de insegurança, que é fomentada pela interferência dos meios de comunicação e, em certas ocasiões, pelas instituições públicas de repressão da criminalidade, contribui para o aumento da sensação de medo em face ao delito, permitindo percepções inexatas da realidade (SÁNCHEZ, 2013). Este processo de recrudescimento da repressão, amparado pela globalização e desenvolvimento tecnológico, está baseado no discurso da insegurança social em prol de uma segurança que nunca chega (BAUMANN, 1999).

Então, passa-se à concepção da existência de um inimigo a ser combatido, com base na necessidade absoluta de segurança. Essa ideia de reagir com o direito penal denota o endurecimento das normas, que ocorre muitas vezes em detrimento das garantias constitucionais. O direito penal do inimigo visa combater as pessoas que, em seu comportamento, em sua vida econômica ou mediante sua incorporação a uma organização, têm se afastado de maneira duradoura do direito (JAKOBS, 2018). Dessa forma, para os cidadãos, a pena seria uma forma de afirmação dos valores positivos do ordenamento jurídico, ao passo que para os estigmatizados como inimigos a pena seria permitida, bem como a flexibilização dos direitos e garantias, em prol da segurança e da guerra contra os males provocados por esses indivíduos entendidos como inimigos.

Em contrapartida, Zaffaroni (2016) afirma que o conceito de inimigo é incompatível com o estado de direito, uma vez que enseja o reconhecimento de um estado absoluto, portanto, que não pode ser 
aceito por ser inconstitucional. A influência da política criminal de guerra contra às drogas, que tem a figura do traficante como inimigo, é percebida na Lei no 11.343/2006 (BRASIL, 2006), na qual houve um endurecimento da pena mínima para o tráfico de drogas em relação à legislação anterior (KARAM, 2017).

O aumento da intervenção penal é contaminado pelo discurso da insegurança, cultura do medo e indignação contra os criminosos, apoiado pela opinião pública e pelos meios de comunicação, com a certeza de que a aplicação dessas leis trará mais segurança (BATISTA, 2002). Permanece nas mãos das agências policiais realizar o primeiro filtro da criminalização secundária, uma vez que são elas que têm o primeiro contato com o suspeito de cometimento de um crime. E, a partir do conhecimento de um fato contrário à lei, podem dar seguimento à investigação ou podem escolher os casos de acordo com sua capacidade técnica e operacional (ANDRADE, 2015).

Nesse contexto, uma enorme quantidade de casos não será conhecida pelas instâncias oficiais, o que compõe as cifras ocultas. Para a realização deste filtro, a polícia atua com certa discricionariedade, uma vez que se utiliza da sua percepção pessoal de mundo para escolher as pessoas a abordar durante a ronda policial, pessoas que estariam no que se chama de "atitude suspeita". Ou, ainda, a polícia espera o cidadão provocar a atuação policial por entender se encontrar em uma situação de risco (CARVALHO, 2013).

\section{METODOLOGIA}

Este trabalho utilizou a análise de conteúdo, a qual permite a descrição sistemática, objetiva e quantitativa do conteúdo da comunicação (MARCONI; LAKATOS, 2010). A técnica utilizada foi a análise categorial, por meio da qual desenvolveu-se o método sob o enfoque quantitativo e qualitativo dos dados.

Quanto ao enfoque quantitativo, foi aplicada a técnica estatística descritiva de dados (BUSSAB, MORETIN, 2013), com a utilização de tabelas, a fim de tornar mais objetiva a interpretação dos dados, possibilitando sua melhor visualização. Com relação ao enfoque qualitativo, foram seguidas as três fases da análise de conteúdo descritas por Bardin (1977): (I) pré-análise, momento em que se realizou a leitura detalhada das sentenças, a fim de extrair as ideias para interpretação dos dados; (ii) exploração do material, que se desenvolveu por meio da construção das categorias, a partir das informações extraídas das sentenças selecionadas, as quais foram agrupadas em unidades de registro para o refinamento em categorias primárias e secundárias de acordo com o assunto pesquisado; e (iii) tratamento dos resultados, inferência e interpretação: realizou-se a análise do material sistematizado, com respaldo no marco teórico escolhido. Desta forma, a partir das informações extraídas das sentenças, foi possível inferir os conhecimentos necessários para interpretar o resultado da pesquisa. O local da pesquisa foi o município de Belém (PA), mais especificamente, a Vara de Combate ao Crime Organizado do Tribunal de Justiça deste município.

Foi utilizado o inteiro teor das sentenças condenatórias relacionadas aos crimes de tráfico de drogas e associação ao tráfico, descritos nos artigos 33 e 35, da Lei n 11.343/2006 (BRASIL, 2006), de onde se extraíram elementos do relatório e da fundamentação das sentenças, a fim de caracterizar as sentenças condenatórias pelo crime de tráfico de drogas, no ano de 2017.

O levantamento das sentenças da Vara de Combate ao Crime Organizado da cidade de Belém foi realizado por meio de consulta à base de dados disponibilizada no sítio eletrônico de domínio público do Tribunal de Justiça do Estado do Pará. Foram incluídas no estudo as sentenças condenatórias de acusados do sexo masculino e feminino processados por crime de tráfico de drogas. Não foram analisadas 
as sentenças absolutórias e sentenças de restituição de coisas apreendidas. Após os filtros utilizados, foram selecionadas 79 sentenças, prolatadas por magistrados diferentes. Em seguida, extraíram-se as informações das sentenças, as quais foram organizadas em tabelas, para auxiliar na discussão dos resultados da pesquisa, levando-se em consideração o referencial teórico escolhido.

Destaca-se que não foi realizada consulta física aos processos e todas as informações foram extraídas do conteúdo das sentenças disponíveis no site do Tribunal de Justiça do Estado do Pará. Para o estudo das sentenças, utilizou-se uma tabela, contendo o máximo de informações acerca das decisões, com intuito de realizar a análise qualitativa dos dados coletados, a partir do referencial teórico utilizado.

Nesse contexto, a análise do conteúdo das sentenças buscou, primeiramente, os dados que as compunham, quais sejam: número do processo, extratos do relatório, da fundamentação e do dispositivo da sentença, para entender como foi feita a investigação em cada processo e quais provas foram consideradas importantes para fundamentar as sentenças. Em seguida, passou-se à análise dos fundamentos utilizados pelos Poder Judiciário para proferir a condenação nos autos consultados. Depois, passou-se à exploração do material, na qual foi realizada a análise dos dados, fazendo um processo de codificação, classificação e categorização das sentenças estudadas. Após a categorização, passou-se à divisão em unidades de contexto e unidades de registro, de onde foram extraídos trechos relacionados à frequência estabelecida. Finalmente, realizou-se o tratamento dos resultados, com a inferência e interpretação, com base no referencial teórico escolhido.

\section{RESULTADOS E DISCUSSÃO}

Inicialmente, aplicou-se análise categorial - que toma em consideração "a totalidade de um texto, passando pelo crivo da classificação e do recenseamento, segundo a frequência de presenças (ou ausências) de itens de sentido" (BARDIN, 1977, p. 36). No processo de categorização utilizou-se a técnica de "caixas": "fornecido o sistema de categorias e repartem-se da melhor maneira possível os elementos, à medida que vão sendo encontrados" (BARDIN, 1977, p. 36). Neste caso específico, consideraram-se as seguintes categorias primárias: (a) formas da abordagem policial; (b) razão da abordagem policial; (c) fundamento para condenação (Tabela 1). Essas categorias foram previamente definidas para promover a caracterização das sentenças condenatórias do crime de tráfico de drogas, da Vara de Combate ao Crime Organizado de Belém (PA), em 2017. O resultado da codificação indicou as seguintes frequências: fundamento para a condenação ( $N=166)$, razão da abordagem policial $(N=95)$, formas de abordagem policial $(N=51)$ (Tabela 1).

\section{TABELA 1}

Número de sentenças condenatórias por tráfico de drogas da Vara de Combate ao Crime Organizado, por categorias primárias e secundárias.

Belém, 2017.

\begin{tabular}{|l|c|}
\hline Categorias primárias e secundárias & N \\
\hline Fundamento para a condenação & 166 \\
\hline Depoimento de testemunhas policiais & 118 \\
\hline Quantidade de drogas & 21 \\
\hline Confissão & 17 \\
\hline Depoimento de outras testemunhas que não são policiais & 7 \\
\hline Interceptação telefônica & 3 \\
\hline
\end{tabular}




\begin{tabular}{|l|r|}
\hline Categorias primárias e secundárias & N \\
\hline Razão da abordagem policial & 95 \\
\hline Denúncia anônima & 52 \\
\hline Atitude suspeita & 22 \\
\hline Operação policial & 11 \\
\hline Prisão em flagrante por outras razões & 7 \\
\hline Interceptação telefônica & 3 \\
\hline Formas de abordagem policial & 51 \\
\hline Policiamento ostensivo & 46 \\
\hline Fazer campana & 5 \\
\hline
\end{tabular}

\section{FUNDAMENTO PARA A CONDENAÇÃO}

A categoria primária intitulada "Fundamento para a condenação" recebeu maior frequência e foi composta por cinco subcategorias: (1) depoimento de testemunhas policiais ( $n=118 ; 71,08 \%)$; (2) quantidade de drogas ( $n=21 ; 12,65 \%)$; (3) confissão ( $n=17 ; 10,24 \%)$; (4) depoimento de outras testemunhas que não são policiais ( $n=7 ; 4,22 \%)$; (5) interceptação telefônica ( $n=3 ; 1,81 \%$ ) (Tabela 1 ).

Segundo o art. 93, inciso IX, da Constituição Federal (BRASIL, 1988), o Poder Judiciário deve fundamentar suas decisões, sob pena de nulidade, em observância ao princípio do livre convencimento motivado. Desta maneira, o juiz pode valorar livremente as provas, atribuindo-lhes a força e o valor que entender cabíveis, devendo indicar os motivos que formaram seu convencimento (BULOS, 2000). Neste sentido, o art. 155 do Código de Processo Penal (BRASIL, 1941) estabelece o livre convencimento motivado ou a persuasão racional, segundo o qual não há regras objetivas e critérios matemáticos de julgamento, cabendo ao juiz formar sua convicção pela livre apreciação das provas, devendo balizar quais provas terão relevância para fundamentar a decisão (LOPES JR., 2018).

O fundamento das sentenças, na maioria dos casos, gira em torno da credibilidade aferida aos testemunhos de policiais envolvidos na abordagem dos réus denunciados. Em 91,13\% das sentenças analisadas, 0 depoimento dos policiais é a única prova testemunhal utilizada para embasar a condenação, além da prova pericial, ou seja, em apenas 7 (4,22\%) processos foram ouvidas outras testemunhas que não eram policiais, assim como a interceptação telefônica foi pouco utilizada como meio de prova, em apenas 3 oportunidades (1,81\%) (Tabela 1). Este resultado reafirma o entendimento doutrinário e jurisprudencial de que a palavra dos policiais tem a mesma validade probante do restante da prova colhida, de forma que não deve ser recebida com ressalvas.

A importância conferida ao depoimento dos policiais é fundamentada na ideia de que, no exercício da função pública, os agentes policiais atuam dentro da legalidade, fundados nos princípios da impessoalidade e da probidade, inerentes aos atos da administração pública, nos termos do art. 37, caput, da Constituição Federal do Brasil (BRASIL, 1988). Ocorre que, segundo Lopes Jr. (2018), deve haver um filtro acerca da credibilidade das informações prestadas, devendo o magistrado ter cautela na valoração dos depoimentos, uma vez que os policiais trazem sua perspectiva em razão da atuação que tiveram na repressão e apuração dos fatos, portanto, buscarão legitimar os atos praticados durante a investigação e prisões, de acordo com sua concepção pessoal. 
Por certo que a defesa tem direito de arrolar testemunhas também, entretanto, o inquérito policial é um procedimento conduzido por policiais, que tem em suas mãos a possibilidade de estipular o que será investigado e o que será registrado nos autos (MISSE, 2011). Para Misse (2010), o inquérito policial, por ser um instrumento inquisitorial, em que não há contraditório nem produção de provas e depoimentos que interessem à defesa, reúne o estatuto da neutralidade da investigação policial com a potencial atribuição da formação da culpa, com a produção de provas no sentido de esclarecer os fatos e demonstrar a autoria do crime. Desta forma, na visão de Misse (2011), o inquérito policial se torna a peça mais importante do processo de incriminação no Brasil, interligando o conjunto do sistema, desde o indiciamento de suspeitos até o julgamento, o que facilita o processo de incriminação dos demais agentes do controle social.

Para Carvalho e Weigert (2018), com intuito de evitar arbitrariedades policiais, é interessante que o princípio da regularidade dos atos dos poderes públicos, em relação à atividade policial, esteja sujeito à refutabilidade. Tais provas devem ser observadas de maneira criteriosa, uma vez que pressupõe que uma situação em que as agências policiais observaram rigidamente os limites constitucionais de atuação está conjugada com a ausência total de outras provas, bem como com a coerência dos relatos dos policiais, sob pena de absolvição do acusados, em observância do princípio do in dubio pro reo (CARVALHO; WEIGERT, 2018). Portanto, a existência do ato por si só não o torna válido (legítimo), uma vez que a legitimidade se relaciona a sua conformidade com a Constituição Federal (BRASIL, 1988).

Aspecto interessante verificado nas sentenças foi relacionado à quantidade de drogas apreendida. $\mathrm{O}$ art. 42 da Lei no 11.343/2006 (BRASIL, 2006) prevê que a natureza e quantidade de drogas sejam consideradas pelo juiz na fixação da pena. Em 59,70\% das sentenças estudadas, a quantidade de drogas encontrada foi de até 100 gramas. Na Tabela 1, nota-se que a quantidade de drogas foi utilizada na fundamentação da sentença para embasar a condenação em 21 (12,65\%) sentenças. Entre essas sentenças, a quantidade de drogas apreendida foi maior que um quilo em seis casos; em três sentenças, a quantidade foi de até um quilo; em nove sentenças, a quantidade foi de até 100 gramas e, em três sentenças, não havia valores em quilos, apenas em embrulhos. Dessa forma, na maioria dessas sentenças, a quantidade de drogas apreendida foi pequena, mas ainda assim utilizada como um dos fundamentos da condenação.

Em 17 (10,24\%) sentenças os acusados confessaram o cometimento do delito, entretanto, pleitearam em tese de defesa a desclassificação para o crime de porte de drogas para uso pessoal, previsto no art. 28, da Lei nº 11.343/2006, todavia, não obtiveram êxito.

Para exemplificar esta subcategoria, em uma das sentenças está descrito que "o denunciado disse em juízo que foi apenas comprar uma massa para consumir". Nesta sentença, o réu foi preso em flagrante por tráfico de drogas por armazenar 100 gramas de maconha e foi condenado por tráfico de drogas. Em outro exemplo, o réu foi condenado por ter em depósito 20,600 gramas de cocaína. Consta da sentença que "Não há que se falar em desclassificação do crime de tráfico para uso de entorpecente porque a qualidade (cocaína) e quantidade (mais de vinte gramas) de entorpecente apreendido não é compatível com o uso próprio".

A legislação brasileira não estabelece parâmetros precisos para determinar quem é o usuário de drogas e quem é o traficante, uma vez que é composta de vários dispositivos vagos e indeterminados. De fato, o art. 33 da já referida lei estabelece, entre outras, as mesmas modalidades típicas que estão previstas no art. 28 do mesmo diploma legal. Para diferenciar o traficante do usuário, o artigo 28 , $\S 2^{\circ}$, prevê que deve ser considerada "a natureza e a quantidade de drogas apreendidas, o local e as condições em que se 
desenvolveu a ação delituosa, as circunstâncias sociais e pessoais do agente, bem como seus antecedentes criminais", o que favorece a violação de garantias individuais, segundo Carvalho (2016).

Na visão de Boiteux (2012), esta característica da lei estabelece amplos poderes aos agentes estatais, iniciando pelo policial, que faz a prisão, e prosseguindo com o Ministério Público, que propõe a ação penal, e finalizando com o magistrado. Apesar da previsão de medida despenalizadora para usuário de drogas, segundo pesquisa realizada por Grillo, Policarpo e Verissimo (2011) no Rio de Janeiro, o que se nota é a diminuição dos flagrantes pelo crime de porte de drogas para uso pessoal e um aumento dos flagrantes relacionados ao crime de tráfico de drogas. De acordo com esses autores, a legislação atual sobre drogas favorece a ocorrência de práticas policiais arbitrárias, na medida em que os registros de ocorrência se tornaram uma espécie de mercadoria política a ser negociada informalmente pela polícia, que tem o primeiro contato com o suspeito e pode decidir discricionariamente se houve tráfico ou porte ilegal de drogas para uso pessoal.

\section{RAZÕES DA ABORDAGEM POLICIAL}

Observa-se que a razão da abordagem policial foi composta por cinco subcategorias: (1) denúncia anônima; (2) atitude suspeita; (3) interceptação telefônica; (4) operação policial; (5) prisão em flagrante por outras razões. O termo "denúncia anônima" ( $n=52 ; 65,82 \%)$ foi o que apareceu com maior frequência nas sentenças. Em seguida, constaram os termos "atitude suspeita" ( $n=22 ; 23,16 \%$ ), "operação policial" ( $n=11 ; 11,58 \%$ ), "prisão em flagrante por outras razões" ( $n=7 ; 7,37 \%)$, que compreende as prisões em flagrante, seja em razão de abordagem no aeroporto ou rodoviária, seja na delegacia ou no presídio; e "interceptação telefônica" ( $n=3 ; 3,16 \%$ ) (Tabela 1).

Em uma análise quantitativa, o motivo mais utilizado para embasar a abordagem policial foi a denúncia anônima, em 46,84\% ( $n=37$ ) das sentenças, e a atitude suspeita, em $25,32 \%(n=20)$ das sentenças. Na perspectiva de Rosa (2016, p. 449), não se sabe ao certo o que os policiais consideram por "atitude suspeita" e não se pode aceitar como normal a atuação utilizada pela polícia de abordar indiscriminadamente os potenciais suspeitos, de acordo com sua percepção, uma vez que isso pode ensejar muitas arbitrariedades e viola os princípios constitucionais da presunção de inocência e da dignidade da pessoa humana, conforme o artigo 1º, inciso iii, e o artigo $5^{\circ}$, inciso LVII, da Constituição (BRASIL, 1988).

O Supremo Tribunal Federal, em decisão com repercussão geral, decidiu que a entrada forçada em residência sem mandado judicial apenas se legitima quando amparada em fundadas razões, justificadas pelas circunstâncias do caso concreto, que indiquem estar ocorrendo, no interior da casa, situação de flagrante delito (BRASIL, 2010). Dessa forma, a ausência de elementos seguros a legitimar a ação dos policiais, diante da discricionariedade na identificação de situações suspeitas, relativas ao tráfico de drogas, pode tornar írrito o direito à intimidade e à inviolabilidade domiciliar. A mera intuição acerca da ocorrência da traficância não configura, por si só, justa causa para permitir o ingresso no domicílio do suspeito, sem seu consentimento e sem determinação judicial (BRASIL, 2019c).

No mesmo sentido, o Superior Tribunal de Justiça entendeu que a mera intuição acerca de possível traficância praticada pelo suspeito pode ensejar abordagem policial em via pública para averiguação, entretanto, não configura justa causa para adentrar o domicílio do suspeito sem mandado judicial, tampouco sem o consentimento do morador, o que deve ser devidamente comprovado (BRASIL, 2017a). A corte superior posicionou-se no sentido de que o ingresso da autoridade policial no interior do domicílio 
do agente suspeito, sem a expedição de mandado de busca e apreensão, deve ser precedido de fundadas suspeitas da prática de crime, como exemplo, denúncias apontando o acusado como traficante do local, somado ao fato de que os policiais visualizaram o acusado portando certa quantidade de drogas, antes de adentrarem o domicílio. A mera denúncia anônima, desacompanhada de outros elementos que indiquem a ocorrência do delito, não legitima o ingresso de policiais no domicílio indicado, não existindo justa causa para o ingresso no domicílio (BRASIL, 2019a, 2019 b).

Cruz e Pylro (2017) entendem que o significado das expressões "elemento suspeito", "fundada suspeita" ou "atitude suspeita" está introjetado na população também, a qual liga para a polícia e relata que determinado elemento está "realizando atividade suspeita". Desta forma, não é somente a polícia que desconfia ou suspeita, mas qualquer pessoa que observa uma cena que considera fora do normal constrói esta percepção da realidade. Todavia, o resultado será o mesmo, uma vez que fica a cargo do policial identificar este indivíduo e realizar a abordagem policial, com base na fundada suspeita própria ou de terceiros. Os autores realizaram pesquisa com policiais em Vila Velha, no Espírito Santo, e destacam que os elementos concretos que mais foram elencados pelos policiais entrevistados foram os relacionados aos sentidos visuais, como tipos de roupas, tatuagens, bonés e condões. Quanto aos elementos sensíveis, estão relacionados dentro da percepção policial como nervosismo horário, alteração de comportamento, mudança de direção e reação à presença policial. Entretanto, o local em que a pessoa se encontra é o que mais influencia a possível abordagem realizada. Dessa forma, se o cidadão circula por uma área de intenso tráfico de drogas, a chance de ser abordado por policiais é grande.

Interessante destacar que, além desses elementos concretos observados pelos policiais, 64\% da população prisional é composta por negros (BRASIL, 2017c) e no Pará este número aumenta para 83\% das pessoas privadas de liberdade, o que evidencia a propensão para a criminalização de pessoas negras no Brasil. Pinc (2014), em pesquisa com policiais militares que trabalhavam no policiamento da cidade de São Paulo, em 2013, colheu dados sobre a percepção dos policiais a respeito de diferentes aspectos da abordagem, em especial da fundada suspeita e da influência da raça/cor e da condição socioecônomica na tomada de decisão policial. Os respondentes da pesquisa discordaram a respeito do maior envolvimento de negros com o crime, em relação a brancos. Pinc (2014) conclui que a abordagem policial é uma prática banalizada e estimulada pelos gestores e amplamente solicitada pela população. Questiona, assim, até que ponto os fatores ensejados da fundada suspeita encontram-se presentes nas abordagens policiais, uma vez que a abordagem sem motivo incorre em violação de direitos civis.

Nesse sentido, o Superior Tribunal de Justiça entende que, apesar de a realidade brasileira sujeitar os policiais a situações de risco, em que devem tomar decisões urgentes no desempenho de suas funções, não se pode olvidar que, ocasionalmente, a ação policial submete pessoas a situações abusivas e arbitrárias. A coletividade precisa se sentir segura e ver seus mínimos direitos e garantias constitucionais preservados. Dessa forma, a inviolabilidade de domicílio não pode ser rechaçada sem elementos concretos de convicção, sob a justificativa de que o local é ponto de venda de drogas ou que ali o suspeito se alocou (BRASIL, 2017b). Após análise detida das sentenças estudadas na pesquisa, não foi possível identificar nos autos a fundada suspeita que ensejou a abordagem policial, uma vez que consta descrita na sentença de forma genérica.

As subcategorias secundárias "operação policial" e "interceptação telefônica" ficaram entre as três menos frequentes na categoria da razão da abordagem policial. Em apenas oito sentenças verificou-se investigação de inteligência, seja por meio de interceptação telefônica ( $n=3)$, seja por meio de operações policiais ( $n=5)$, que resultaram em busca e apreensão de drogas ou em pedido de prisão. 


\section{FORMAS DA ABORDAGEM POLICIAL}

A categoria principal sobre formas de abordagem policial foi composta por duas subcategorias: (1) policiamento ostensivo e (2) fazer campana (Tabela 1). O termo "policiamento ostensivo" apareceu na maioria das sentenças ( $n=46 ; 90,20 \%$ ) e em $37(46,84 \%)$ o policiamento ostensivo constituiu a forma de abordagem policial mais encontrada. Este resultado é evidenciado pelo fato de que $96(92,41 \%)$ prisões foram em flagrante delito e 6 (7,59\%) prisões ocorreram em razão de mandado judicial.

Na perspectiva de Gomes (2016), que realizou pesquisa na $9^{a}$ Vara Criminal de Belém, nos processos relacionados aos crimes da Lei n 11.342/2006, a polícia civil não costuma fazer uma investigação ativa dos crimes de drogas, com utilização de medidas processuais importantes para a descoberta da verdade real, onde se busque amealhar a maior quantidade possível de provas. Descumpre, assim, o art. $6^{\circ}$, III, do Código de Processo Penal, o qual estabelece que a autoridade policial, ao tomar conhecimento de uma conduta criminosa, deve colher todos os elementos de provas, a fim de esclarecer os fatos e suas circunstâncias. De acordo com o autor, a maneira de atuação dos policiais demonstra como são desenvolvidos os discursos dos agentes do sistema penal, no qual se reproduz a ideia do senso comum de quem seja o criminoso. Os policiais olham para o indivíduo na rua e entendem que ele faz parte de uma determinada categoria de desviantes, seja pelo modo como está vestido, seja pelo bairro em que foi encontrado.

Por certo, que o inquérito policial é um instrumento de investigação preliminar não obrigatório, que produz elementos com valor de meros atos de investigação. As provas produzidas devem ser ratificadas em juízo e o inquérito pode ser dispensado pelo Ministério Público, caso disponha de elementos para a imediata propositura da ação penal (LOPES JR., 2018). Ocorre que, da maneira como as provas são produzidas durante a investigação preliminar, as mesmas provas são reproduzidas e ratificadas em juízo (VALOIS, 2014). Nesse sentido, Misse (2011) entende que o inquérito policial se transformou em uma peça, que poupa o trabalho dos demais operadores do direito no processo de incriminação. Valois (2017), a partir de pesquisa realizada em 250 inquéritos de tráfico de drogas das capitais de São Paulo, Rio de Janeiro, Rio Grande do Sul e Minas Gerais e do Distrito Federal, conclui que a polícia judiciária apenas ratifica os atos praticados pela polícia que atua na repressão nas ruas, normalmente a militar, reduzindo a termo o testemunho de policiais, condutor e demais testemunhas, caso existentes. Dessa maneira, haveria um contraditório apenas na forma, em evidente prejuízo à defesa, uma vez que a ausência de outras testemunhas que possam ratificar o testemunho de policiais dificulta o trabalho da defesa, que possivelmente não identifica quem estava presente no momento da prisão e que possa depor a favor do acusado (VALOIS, 2017). Para o autor, o que chega para o magistrado são somente as provas colhidas por policiais, que são revistas sob o manto do contraditório em juízo. A paridade de armas, nos processos de tráfico de drogas, torna-se mitigada, pois o contraditório na esfera judicial serve como um complemento, como uma legitimação do que foi produzido na polícia, em vez de o inquérito policial servir de complemento às provas produzidas em juízo (VALOIS, 2017).

\section{ANÁLISE LÉXICA}

A análise léxica refere-se à parte quantitativa da análise de conteúdo, tendo sido realizada por meio da técnica de análise de frequência, que toma por base a lexicologia, que é aplicada ao "estudo científico do vocabulário, e a estatística lexical, aplicação dos métodos estatísticos à descrição do vocabulário" (BARDIN, 1977, p. 44). Para tanto, identificou-se a frequência absoluta das palavras em um corpus textual. 
Neste estudo, decidiu-se comparar a estrutura lexical de dois trechos das sentenças estudadas, que são (i) relatório e (ii) fundamentação. Para visualização dos outputs da técnica adotou-se o estilo nuvem de palavras, que indica as palavras ou conceitos mais incidentes (BARDIN, 1977), com os seguintes critérios: (a) 50 palavras mais frequentes; (b) termos com seis ou mais caracteres (Figura 1).

\section{FIGURA 1}

Nuvens de palavras mais frequentes do relatório e da fundamentação das sentenças condenatórias por tráfico de drogas da Vara de Combate ao Crime Organizado.

\section{Belém, 2017.}

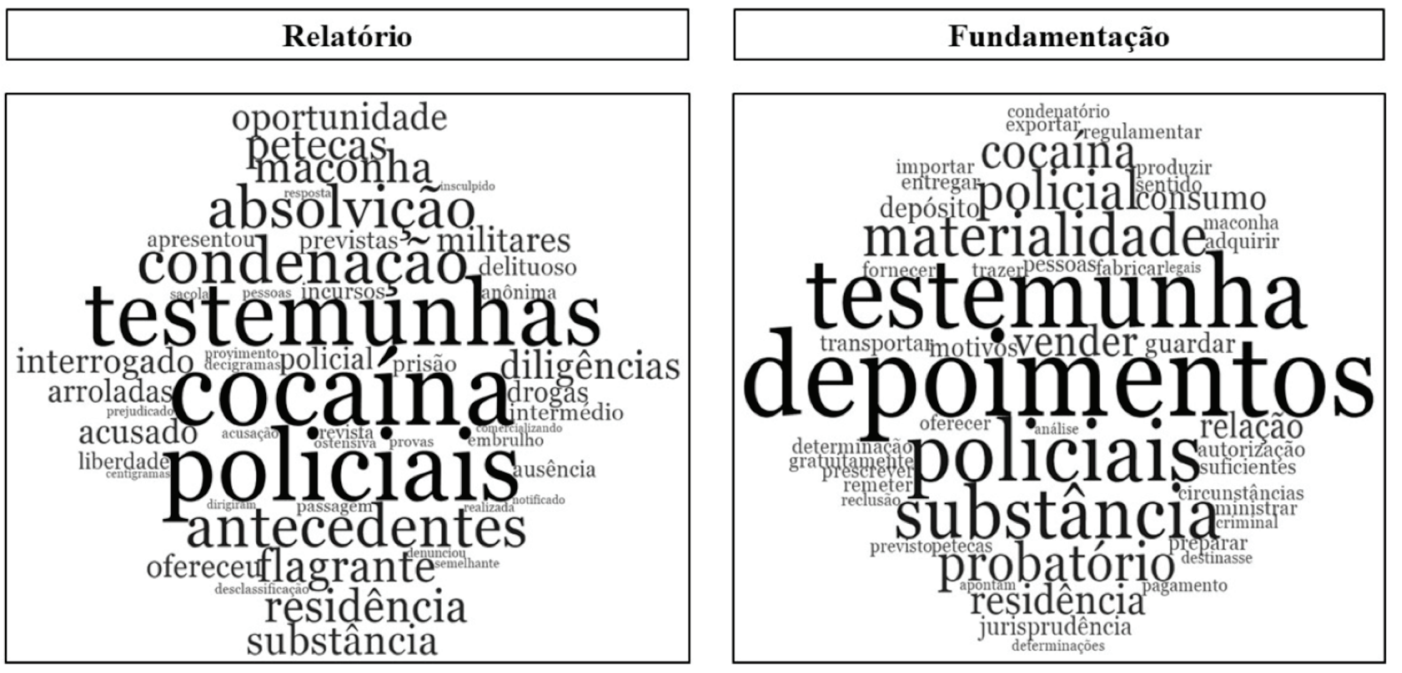

Nota: Selecionaram-se as 50 palavras com 6 ou mais caracteres que se mostraram mais frequentes em cada trecho das sentenças condenatórias.

Para compreensão das nuvens de palavras, extraídas do software Nvivo (Figura 1), deve-se considerar que quanto maior a palavra na nuvem, mais frequente ela é no corpus textual. Com esta técnica, atribuem-se níveis de importância aos termos considerando o número de ocorrências. Ressalta-se que foram excluídos termos conectores, bem como algumas expressões comuns à escrita de todas as sentenças criminais, por exemplo: defesa, denúncia, Ministério Público, alegações, etc.

Os termos mais evidentes no relatório da sentença foram: ( () antecedentes $(n=12)$; (ii) testemunhas $(n=11)$; (iii) condenação ( $n=10)$; (iv) policiais $(n=9)$, (v) cocaína $(n=7)$. E na fundamentação da sentença foram: ( () materialidade ( $n=13)$, (ii) depoimentos ( $n=11)$, (iii) testemunha $(n=10)$, (iv) substância $(n=10)$ e (v) policiais $(n=9)$. Verifica-se que tanto no relatório quanto na fundamentação as palavras "policiais" e "testemunha(s)" obtiveram destaque, as quais foram utilizadas juntas na subcategoria "depoimento de testemunhas policiais" da categoria principal "fundamentação para a condenação" (Tabela 1). A palavra "cocaína" também se destacou (Figura 1), uma vez que a droga encontrada na maioria das sentenças ( $n=51 ; 64,56 \%)$ foi a cocaína.

Na fundamentação, a palavra "depoimentos" foi evidenciada juntamente com "policiais" e "testemunhas", o que comprova a importância dessas palavras nas sentenças analisadas (Figura 1): a condenação baseiase, em sua maioria, na prova testemunhal, principalmente o depoimento de policiais. As palavras "materialidade" e "substâncias" se relacionaram à apreensão de entorpecentes, enfatizando que a materialidade da ocorrência do crime relacionado a drogas nas sentenças consultadas era comprovada por meio da apreensão de substâncias entorpecentes (Figura 1). 


\section{CONSIDERAÇÕES FINAIS}

O objetivo deste trabalho foi caracterizar as sentenças condenatórias do crime de tráfico de drogas, da Vara de Combate ao Crime Organizado de Belém (PA) em 2017. Para isso, utilizou-se a análise de conteúdo dos dados extraídos das sentenças condenatórias do crime de tráfico de drogas, a partir do qual se estabeleceu uma discussão com a criminologia crítica. De acordo com as sentenças estudadas, a maioria das prisões que originaram o processo criminal foi em flagrante delito, em razão de denúncia anônima ou atitude suspeita, durante o policiamento ostensivo. A hipótese inicialmente estabelecida foi confirmada, na medida em que se verificou que a polícia é importante na definição do que ocorre nos passos seguintes do processo, já que realiza a primeira seleção de pessoas a serem criminalizadas, ao efetivar as suas abordagens.

Verificou-se também que as provas produzidas para embasar a sentença condenatória foram em sua maioria o depoimento de testemunhas policiais, somado ao laudo pericial. A importância do depoimento policial foi assim sublinhada, e na maioria das sentenças constituía a única prova testemunhal utilizada para proferir a condenação. Analisar provas para proferir uma sentença condenatória e aplicar a pena são atividades bastante complexas e demandam uma certa sensibilidade do julgador. A falta de cuidado na condução da investigação criminal pode acarretar consequências para toda a persecução criminal. Apesar da obrigatoriedade de arrolar nos autos testemunhas do fato, nos termos do art. $6^{\circ}$, III, do Código de Processo Penal, o que se nota é apenas a presença de testemunhas de policiais que participaram da prisão em flagrante.

Esta situação se reflete em toda a persecução criminal, uma vez que o Ministério Público termina por fazer a denúncia com base nas provas produzidas no inquérito, pois precisa cumprir o prazo de cinco dias para a propositura da ação penal, sob pena de relaxamento da prisão em flagrante. Apesar da grande complexidade inerente ao ato de decidir, há uma repetição de argumentos, sem que se pare para observar a fundo as nuances de cada caso concreto. O Poder Judiciário reproduz o que já existe no processo, pois julga de acordo com o que the foi trazido nos autos, observando o preceito constitucional de que o Poder Judiciário deve se manter imparcial na solução das causas que lhe são submetidas. Dessa forma, a polícia tem grande influência na atividade do Ministério Público e do Poder judiciário.

Assim, as prisões permanecem superlotadas de traficantes presos com pequena quantidade de drogas, alvos fáceis da repressão policial, pois não apresentam resistência aos comandos de prisão. Nesse contexto, a política de drogas adotada no Brasil precisa ser repensada com urgência, na medida em que a taxa de encarceramento cresce proporcionalmente ao aumento da repressão ao tráfico de drogas, o que demonstra que a estratégia adotada não está surtindo efeito.

Outro ponto a ser observado é a forma como a fase investigatória deve ser conduzida. Não ocorre uma fiscalização efetiva de como são produzidas as provas existentes no inquérito policial. Estas são simplesmente aceitas como verdade. De fato, a polícia tem fé pública e o depoimento de policiais é idôneo para embasar uma sentença condenatória, entretanto, é preciso sopesar com bastante cautela as provas existentes, para evitar que garantias e direitos constitucionais sejam relativizados em favor da guerra contra às drogas vigente no país. 


\section{REFERÊNCIAS BIBLIOGRÁFICAS}

ANDRADE, Vera Regina Pereira de. A ilusão de segurança jurídica: do controle da violência à violência do controle penal. 2.ed. Porto Alegre: Livraria do Advogado, 2015.

BARATTA, Alessandro. Criminologia Crítica e crítica ao Direito Penal: introdução à sociologia do direito do direito penal. 6.ed. Rio de Janeiro: Renan, 2016.

BARDIN, Laurence. Análise de conteúdo. Lisboa: Edições 70, 1977.

BATISTA, Nilo. Mídia e sistema penal no capitalismo tardio. Discursos Sediciosos: crime, direito e sociedade. Rio de Janeiro, v. 7, n. 12, p. 271-288, 2002.

BAUMANN, Zygmund. Globalização. Trad. Marcus Penchel. Rio de Janeiro: Jorge Zahar, 1999.

BRASIL. Ministério da Justiça. Levantamento Nacional de informações penitenciárias - Infopen. Atualização - julho de 2016. Organização por Thandara Santos. Brasília, DF: Ministério da Justiça, 2017.

BRASIL. Código de Processo Penal. Brasília, DF: Senado Federal: Centro Gráfico, 1941.

BRASIL. Constituição da República Federativa do Brasil. Brasília, DF: Senado Federal: Centro Gráfico, 1988. 292 p.

BRASIL. Presidência da República. Lei n 11.343, de 23 de agosto de 2006. Institui o Sistema Nacional de Políticas Públicas sobre Drogas - Sisnad; prescreve medidas para prevenção do uso indevido, atenção e reinserção social de usuários e dependentes de drogas; estabelece normas para repressão à produção não autorizada e ao tráfico ilícito de drogas; define crimes e dá outras providências. Brasília, DF, 2006.

BRASIL. Superior Tribunal de Justiça. Recurso Ordinário em Habeas Corpus 104682/MG, 6. Turma. Relator: Ministro Rogerio Schietti Cruz. DJE, 4 fev. 2019. Disponível em: <http://www.stj.jus.br/SCON/>. Acesso em: 28 set. 2020.

BRASIL. Superior Tribunal de Justiça. Recurso Especial 1558004/RS, 6. Turma. Relator: Ministro Rogerio Schietti Cruz. DJE, 31 ago. 2017a. Disponível em: <http://www.stj.jus.br/SCON/>. Acesso em: 28 set. 2020.

BRASIL. Superior Tribunal de Justiça. Agravo Regimental no Agravo em Recurso Especial 1371623/SC, 6. Turma. Relator Ministra Laurita Vaz. DJE, 30 abr. 2019a. Disponível em: <http://www.stj.jus.br/SCON/>. Acesso em: 28 set. 2020.

BRASIL. Superior Tribunal de Justiça. Recurso Especial 1787855/MG, 6. Turma. Relator Ministro Nefi Cordeiro. DJE, 3 maio 2019b. Disponível em: <http://www.stj.jus.br/SCON/>. Acesso em: 28 set. 2020.

BRASIL. Superior Tribunal de Justiça. Recurso Especial 1574681/RS, 6. Turma. Relator: Ministro Rogerio Schietti Cruz. DJE, 30 maio 2017b. Disponível em: <http://www.stj.jus.br/SCON/>. Acesso em: 28 set. 2020.

BRASIL. Supremo Tribunal Federal. Recurso Extraordinário n. 603.616/RO, Tribunal Pleno. Relator: Ministro Gilmar Mendes. DJE, 8 out. 2010. Disponível em: <http://portal.stf.jus.br/>. Acesso em: 28 set. 2020.

BECKER, Howard. Outsiders: estudos de sociologia do desvio. Tradução Maria Luiza X. Borges. Rio de Janeiro: Zahar, 2008.

BOITEUX, Luciana; PÁDUA, João Pedro. La desproporción de la Ley de Drogas: los costes humanos y económicos de la actual política en Brasil. In: CORREA, Catalina Pérez (Org.). Justicia desmedida: Proporcionalidad y delitos de drogas en America Latina. Ciudad de Mexico: Fontamara, 2012. p. 71-101. 
BOITEUX, Luciana. Drogas e cárcere: repressão às drogas, aumento da população penitenciária brasileira e alternativas. In: SHECAIRA, Sérgio Salomão (Org.). Drogas: uma nova perspectiva. São Paulo: IBCCRIM, 2014. p. 83-103.

BULOS, Uadi Lammêgo. O livre convencimento do juiz e as garantias constitucionais do processo penal. Revista da EMERJ, v. 3, n. 12, p. 184-198, 2000. Disponível em: <http://201.23.85.222/biblioteca/index. asp?codigo_sophia=46927>. Acesso em: 6 mai. 2019.

BUSSAB, Wilson de Oliveira; MORETTIN, Pedro Alberto. Estatística Básica. 8. ed. São Paulo: Saraiva, 2013. CARVALHO, Salo de. Política de drogas: mudanças e paradigmas. Revista da EMERJ, v. 16, n. 63, p. 46-69, out.-dez. 2013.

CARVALHO, Salo de. A política criminal de drogas no Brasil: Estudo criminológico e dogmático da Lei No 11.343/2006. 8.ed., rev. e atual. São Paulo: Saraiva, 2016.

CARVALHO, Salo de; WEIGERT, Mariana de Assis Brasil e. Making a drug dealer: o impacto dos depoimentos policiais e os efeitos da súmula n. 70 do TJRJ na construção do caso Rafael Braga. Revista de Estudos Criminais, v. 17, n. 68, p. 45-77, jan.-mar. 2018.

CONDE, Francisco Muñoz, HASSEMER, Winfried. Introdução à Criminologia. Rio de Janeiro: Lumen Juris, 1985.

CRUZ, Marcio Antônio da; PYLRO, Simone Chabudee. A fundada suspeita e a abordagem policial militar. Confluências: Revista interdisciplinar de sociologia e direito, v. 19, n. 1, p. 64-81, 2017.

GOMES, Marcus Alan de Melo. A Lei 11.343/2006 e a autofagia do sistema penal nos crimes de drogas. In: CARVALHO, Érika Mendes de; ÁVILA, Gustavo Noronha de. (Orgs). 10 anos da lei de drogas: aspectos criminológicos, dogmáticos e político-criminais. Belo Horizonte: D’Plácido, 2016. p. 13-26.

GRILLO, Carolina Christoph; POLICARPO, Frederico; VERISSIMO, Marcos. A "dura" e o "desenrolo": efeitos práticos da nova lei de drogas no Rio de Janeiro. Rev. Sociologia e Política, v. 19, n. 40, p. 135-148, out. 2011.

JAKOBS, Günther. Direito penal do cidadão e direito penal do inimigo. In: JAKOBS, Günther; MELIA, Manuel Cancio. Direito penal direito penal do inimigo: noções e críticas. 6.ed., Porto Alegre: Livraria do Advogado, 2018.

KARAM, Maria Lucia. Considerações sobre as políticas criminais, drogas e direitos humanos. In: VECCHIA, Marcelo Dalla. et al. (Org.). Drogas e direitos humanos: reflexões em tempos de guerra às drogas. 1. ed. Porto Alegre: Rede UNIDA, 2017. p. 222-243.

LOPES JR., Aury. Direito Processual Penal. 15. ed. São Paulo: Saraiva Educação, 2018.

MARCONI, Marina de Andrade; LAKATOS, Eva Maria. Fundamentos de metodologia científica. 7. ed., São Paulo: Atlas, 2010.

MISSE, Michel. O inquérito policial no Brasil: Resultados gerais de uma pesquisa. DILEMAS: Revista de conflito e controle social, v. 3, n. 7, p. 35-50, jan.-mar. 2010.

MISSE, Michel. O papel do inquérito policial no processo de incriminação no Brasil: algumas reflexões a partir de uma pesquisa. Sociedade e Estado, v. 26, n. 1, p. 15-27, abr. 2011.

MONTEIRO, Felipe Mattos; CARDOSO, Gabriela Ribeiro. A seletividade do sistema prisional brasileiro e o perfil da população carcerária: um debate oportuno. Civitas - Revista de Ciências Sociais, v. 13, n. 1, p. 93-117, 2013. 
PINC, Tania. Por que o policial aborda? Um estudo empírico sobre a fundada suspeita. Confluências: Revista interdisciplinar de sociologia e direito, v. 16, n. 3, p. 34-59, 2014.

ROSA, Alexandre Morais da Rosa. A banalização da busca e apreensão nos crimes de tráfico. In: CARVALHO, Érika Mendes de; ÁVILA, Gustavo Noronha de (Org.). 10 anos da lei de drogas: aspectos criminológicos, dogmáticos e político-criminais. Belo Horizonte: D’Plácido, 2016. p. 439-451.

SÁNCHEZ, Jesús-María Silva. A expansão do direito penal: aspectos da política criminal nas sociedades pós-industriais. 3.ed. São Paulo: Revista dos Tribunais, 2013.

SANTOS, Andre Filipe; BROCCO, Pedro. Notas sobre a estigmatização do traficante de drogas para legitimação social das Unidades de Polícia Pacificadora (UPP) no Rio de Janeiro (2010-2011). Cadernos de Direito, v. 16, n. 31, p. 115-144, 2016.

UNODC. United Nations Office on Drug and Crime. World Drug Report 2018. Viena: UNODC, 2018. Sales ก. E.18.XI.9.

VALOIS, Luis Carlos. O direito à prova violado nos processos de tráfico de entorpecentes. In: LEMOS, Clécio; MARONA, Cristiano Ávila; QUINTAS, Jorge. Drogas: uma nova perspectiva. São Paulo: IBCCRIM, 2014. p. 105-130.

VALOIS, Luis Carlos. O direito penal da guerra às drogas. 2. ed. Belo Horizonte: DPlácido, 2017.

ZAFFARONI, Eugenio Raul. O inimigo no direito penal. 3. ed. Rio de Janeiro: Renan, 2016. 
Renata Valeria Pinto Cardoso Lisboa, Edson Marcos Leal Soares Ramos,

Marcus Alan de Melo Gomes e Maély Ferreira de Holanda Ramos

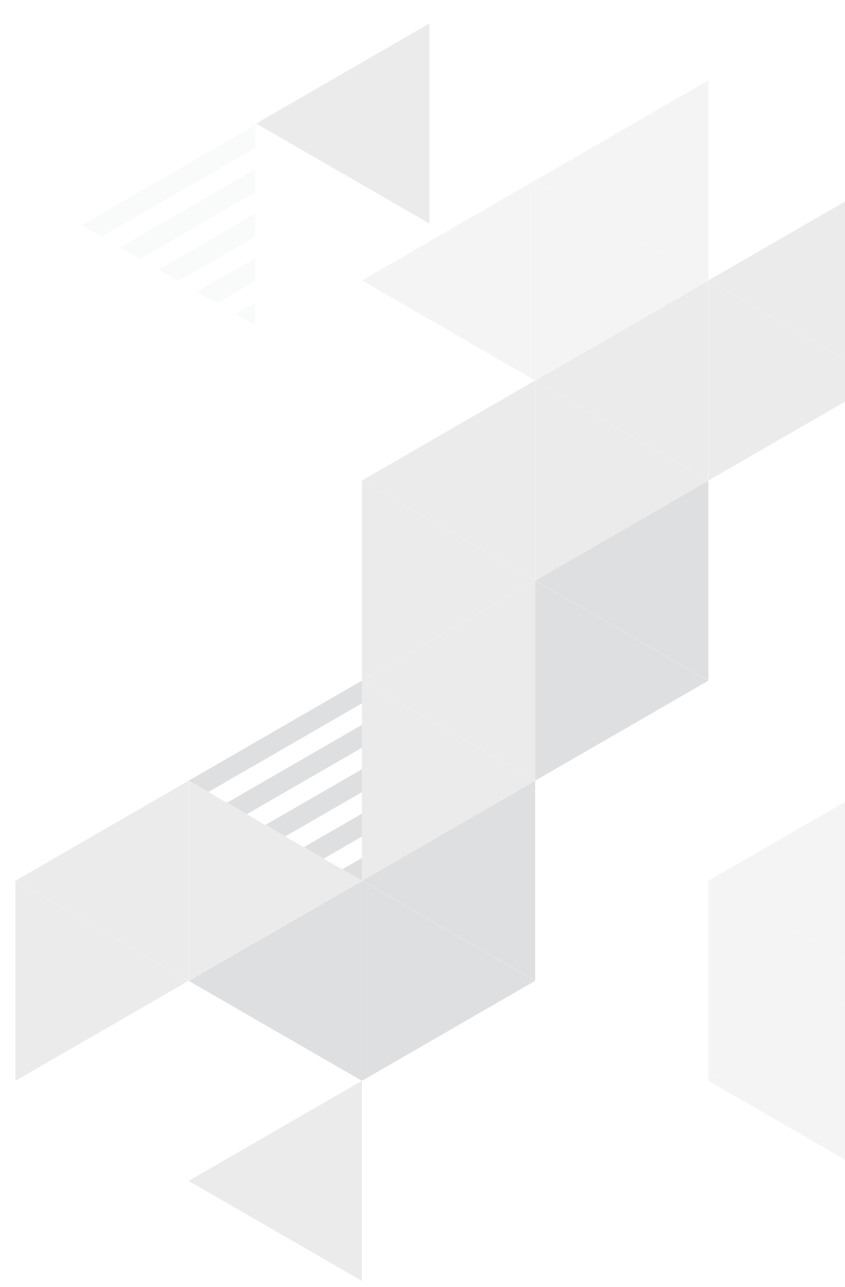

